\title{
POPULAÇÃO, ECONOMIA E TERRITÓRIO: OBSERVAÇÕES INICIAIS SOBRE CONSTRUÇÃO CIVIL E A PRODUTIVIDADE DA MÃO DE OBRA EM GRANDES EMPREENDIMENTOS
}

\author{
Lucas Devides Moreno ${ }^{1}$
}

Bruno Borges Mamede ${ }^{2}$

\section{Luis Otávio Cocito de Araújo ${ }^{3}$}

\section{RESUMO}

Este artigo materializa o início da pesquisa de mestrado do autor principal e pretende abordar a relação a transformação do território a partir das obras de Construção Civil de grandes empreendimentos frente a qualificação da mão de obra disponível e sua distribuição espacial no território brasileiro. Na primeira década do século XXI observa-se um ciclo de crescimento econômico positivo no país e, consequentemente, a construção de grandes empreendimentos no período também aumentou. Entretanto, o ritmo de qualificação da mão de obra, bem com a presença de trabalhadores já especializados nestas obras ainda é muito pequeno frente a grande demanda apresentada pelas empresas nestes novos empreendimentos.

Palavras-Chave: Engenharia Urbana, Engenharia Civil, Produtividade da Mão de Obra.

\section{POPULATION, ECONOMY AND TERRITORY: INITIAL OBSERVATIONS ON CONSTRUCTION AND PRODUCTIVITY OF LABOUR IN LARGE ENTERPRISES}

\section{ABSTRACT}

\footnotetext{
${ }^{1}$ Engenheiro Civil (Mackenzie-SP), Aluno de Mestrado em PEU/POLI/UFRJ, lucas.moreno@poli.ufri.br. 2 Comunicador Social (PUC-Rio) e Geógrafo (UERJ), Aluno de Mestrado em PEU/POLI/UFRJ e de Especialização em IPPUR/UFRJ, bruno.mamede@poli.ufri.br.

${ }^{3}$ Doutor em Construção Civil (USP), Professor em PEU/POLI/UFRJ, luis.otavio@poli.ufri.br.
} 
This article materializes the begging of the main author's research for his master's degree and pretends to analyze the existent relationship the territory's transformation from the Civil Construction of great ventures facing the available workforce qualification and its spatial distribution through Brazilian territory. In XXI century's first decade its noticeable and positive economical cycle in the country and, consequently, the new great ventures construction in the period has also raised. Therefore, the labor force qualification rhythm, also the presence of workers already qualified in these constructions is still too low by the huge demand presented by the companies in these new ventures.

Keywords: Urban Engineering, Civil Engineering, Labor Force Productivity

\section{POBLACIÓN, ECONOMÍA Y TERRITORIO: OBSERVACIONES INICIALES EN LA CONSTRUCCIÓN Y LA PRODUCTIVIDAD DEL TRABAJO EN GRANDES EMPRESAS}

\section{RESUMÉN}

Este artículo materializa el inicio de la investigación de maestría de la autora principal y busca analizar la relación existente entre la transformación del territorio a partir de la Construcción Civil de grandes emprendimientos nuevos frente a la disponibilidad de la fuerza de trabajo disponible y la distribución espacial e el territorio brasileño. Observase en la primera década del siglo XXI un ciclo de crecimiento económico positivo en el país y, consecuentemente, la construcción de nuevos grandes emprendimientos en este período también creció. Entretanto, el ritmo de calificación de la fuerza de trabajo, mas también la presencia de de trabajadores ya calificados en estas construcciones aún es muy baja mediante la gran demanda presentada por la empresas en estos nuevos emprendimientos.

Palabras-Clave: Ingeniería Urbana, Ingeniería Civil, Productividad de Fuerza de Trabajo.

\section{INTRODUÇÃO: PROPOSTA E OBJETIVO}

Este trabalho compõe a etapa inicial da pesquisa de mestrado do autor principal, sendo seu principal questionamento a qualificação da mão de obra brasileira frente ao ciclo de crescimento nacional inicial nos anos 2000. O objetivo deste estudo preocupa-se em mostrar qual a relação da qualidade e quantidade de 
mão de obra disponível no Brasil para suprir sua necessidade de aceleração dos investimentos na construção civil, não apenas em face do elevado déficit habitacional no país, mas também para suprir a grande deficiência em infraestrutura. Faz-se importante lembrar os compromissos assumidos pelo Brasil para a realização de importantes megaeventos internacionais a exemplo da Copa do Mundo em 2014 e dos Jogos Olímpicos em 2016.

Ainda sobre o objetivo, este artigo pretende demonstrar quais são os impactos econômico e social para o Brasil da negligencia dos governantes com o baixo incentivo para uma qualificação e capacitação na mão de obra presente na construção civil. Economicamente falando implica em uma desaceleração no crescimento brasileiro devido à alta da inflação e baixa produtividade, bem como socialmente devido à incapacidade de concluir obras que serviriam como benfeitorias para população elevando os níveis de qualidade de vida.

A justificativa para este estudo está pautada na atualização do debate sobre a qualificação da mão de obra frente a produtividade de obras da Construção Civil. Acredita-se que dentre os custos componentes de um determinado empreendimento, a mão de obra responde pela maior parcela do orçamento inicial e, não apenas isto, mas dependendo de sua qualificação, o desempenho pode ser comprometido e, subsequentemente, impactar outros pontos da cadeia produtiva, a exemplo do consumo de materiais. Ao observar isto frente a quantidade de novos empreendimentos em andamento por todo país, analisar este tema torna-o extremamente atual como também pertinente a dinâmica laboral brasileira.

Desta maneira, a metodologia aqui utilizada consiste basicamente do levantamento e revisão bibliográfica acerca da temática frente a análise de dados recentes sobre o tema para, finalmente, obter conclusões iniciais a cerca da espacialização produtividade da mão de obra brasileira. Muitos locais que estão recebendo estes empreendimentos, a exemplo de grandes construções no estado do Rio de Janeiro, como o Arco Metropolitano (ampliação da BR-493), a construção do corredor BRT TransCarioca (cidade do Rio de Janeiro) e, principalmente, a implantação do novo Complexo Petroquímico do Rio de Janeiro (COMPERJ) no município de Itaboraí, tem demandado contingentes cada vez maiores de mão de 
obra sem que esta, necessariamente, possua a pré-qualificação necessária para o satisfatório desempenho das atividades atribuídas.

Para entendimento da situação atual do Brasil, no que refere-se à disponibilidade de trabalhadores para preencher os desafios da construção civil (idade média da população apta para o trabalho), o conjunto de investimentos disponibilizados pelo governo federal é percebido como prioridade para que o país obtenha um crescimento social e econômico desejável perante as grandes potencias mundiais.

De acordo com estimativas, a partir de 2020 o Brasil enfrentará dificuldades devido à disponibilidade de mão de obra, problema na qual a Europa vem sofrendo atualmente. Segundo Monteiro (2013), o envelhecimento da população europeia e, com isso, a crescente dificuldade no recrutamento de mão de obra para a construção civil criam uma necessidade extrema pela busca por estrangeiros para preenchimentos destas vagas de empregos faltantes.

A falta de investimento no setor da infraestrutura brasileira é histórica. Segundo Munteal (2013), nas décadas de 1980 e 1990, a contribuição governamental na infraestrutura de transporte foi mínima, sendo que os investimentos representavam apenas $0,2 \%$ do PIB anual, enquanto em países como a China, no mesmo período a média foi de 3,5\%. A falta de aporte para esses recursos no período cobrou um alto preço de logística nacional, que movimentou cerca de $\mathrm{R} \$ 350$ bilhões em 2012, o dobro de dez anos atrás, transportando $60 \%$ do que é produzido no país.

Porém o cenário brasileiro tem mudado muito ao longo das ultimas duas décadas. Os governantes começaram a realizar parceiras públicas privadas, para aquecer o setor através de concessões e principalmente investimentos em projetos em infraestrutura como na construção de rodovias, ferrovias, aeroportos, entre outros. Tais investimentos conspiram para uma situação promissora para os brasileiros nos próximos anos.

Serão discutidos aqui alguns programas lançados pelo governo federal, com o intuído de alavancar o setor de infraestrutura brasileira. Em seguida será apresentada a evolução de investimentos realizada pelo Banco Nacional de 
Desenvolvimento Econômico e Social (BNDES), onde serão tiradas algumas conclusões, referente à evolução continua dos investimentos, e a estagnação de estímulos e incentivos referente a qualificações de operários da construção civil, recursos este primordial para o sucesso de tais financiamentos liberados pelo BNDES.

\section{1- POPULAÇÃO, ECONOMIA E TERRITÓRIO}

Segundo o IBGE (2010), a população brasileira atingiu na primeira metade década do século XXI a marca de 190,7 milhões de habitantes. Apesar de ser um dos países mais populosos do mundo, este ritmo de crescimento populacional já aponta sinais de estabilização há algum tempo. A taxa de crescimento populacional dessa primeira década (2000-2010) foi de 1,17\%, muito distante dos $3 \%$ aos anos experimentados na década de 1950-1960 (Ojima, 2013). O Brasil passou por diversas mudanças nos últimos 50 anos, sendo a intensa migração do campo para as cidades uma das principais. O Gráfico 01 - Taxa de Crescimento Geométrico Médio Anual apresenta a tendência esta tendência de elevação e estabilização do crescimento populacional no período.

\section{Gráfico 01: Taxa de Crescimento Geométrico Médio Anual}

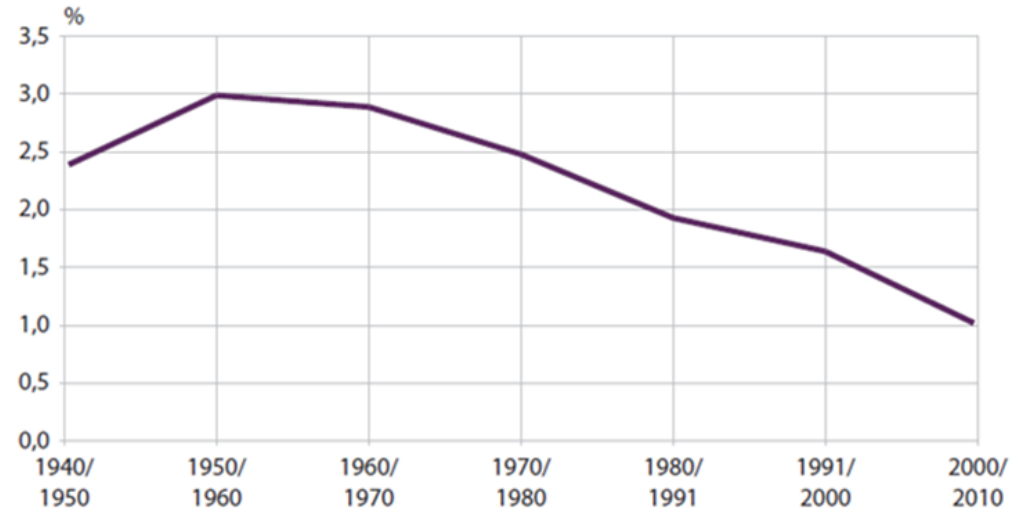

Fonte: IBGE (2010) 
De acordo com Okima (2013), em 2010 mais de 84\% da população está vivendo em áreas classificadas como urbanas. Associado a essa urbanização intensa e acelerada, os modos de vida dessa sociedade também mudou. O Gráfico 02 Projeção da Pirâmide de População Brasileira para o Período de 2000 a 2020 indica um pouco do crescimento e estabilização do país prevista para o período.

\section{Gráfico 02: Projeção da Pirâmide de População Brasileira para o Período de 2000 a 2020.}
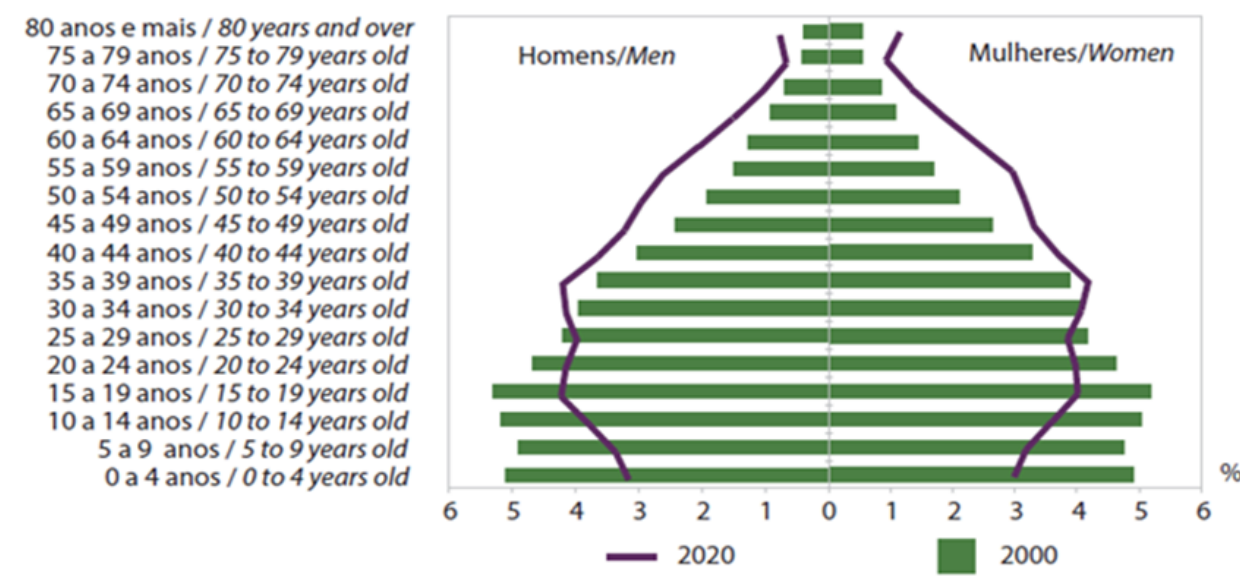

Fonte: IBGE (2010)

A situação do crescimento populacional chama a atenção para duas temáticas: a primeira referente ao panorama referente ao déficit habitacional brasileiro decorrente da alta urbanização a partir dos anos 1950 e a segunda diz respeito à população brasileira ativa para o trabalho, devido à queda na taxa de crescimento populacional no inicio do século XXI.

A Conferência das Nações Unidas sobre Assentamentos Humanos - HABITAT II realizado em Instambul em 1996 teve como objetivo discutir como e onde moram os habitantes da Terra. O compromisso de aceitar de forma progressiva que se torne realidade o direito á moradia para todos foi firmado pelo Brasil e diversas outras nações. Programas especiais, objetivando examinar as soluções utilizadas para melhorar a qualidade de vida em centros urbanos, tendo como critérios eficientes na reabilitação de áreas degradadas, uso do desenvolvimento sustentado e grau de inovação, foram selecionados para organização do evento. Afirmou-se na 
conferência, que uma moradia adequada também significa privacidade adequada, espaço adequado, acesso físico, segurança adequada, estabilidade e durabilidade estrutural, iluminação, aquecimento e ventilação adequada, infraestrutura básica adequada, como abastecimento de água e facilidades sanitárias e de coleta de lixo; qualidade ambiental saudável e adequada; localização adequada e acessível em relação ao trabalho e facilidades básicas, tudo em um custo razoável. A adequação deveria ser determinada de forma conjunta com as pessoas interessada, tendo em vista um desenvolvimento gradual.

O mercado imobiliário brasileiro vem apresentando um potencial de expansão muito grande. Segundo a Fundação João Pinheiro (2014), o déficit habitacional brasileiro oscila entre 5,2 milhões e 6,9 milhões de residência, a fundação ainda diz que o déficit habitacional é a necessidade de construção de novas moradias para que a resolução de problemas sociais detectados em um certo momento e específicos da habitação.

O tamanho do território brasileiro e a necessidade de crescimento econômico, corroboram-se por uma necessidade estrema de um plano de crescimento da infraestrutura brasileira, onde o seu sucesso é diretamente proporcional a uma mão de obra disponível e qualificada para tais obras.

A infraestrutura é a base para um desenvolvimento econômico de um país. Segundo Gouvêa (2005), a infraestrutura é caracterizada por um conjunto de atividades e estruturas da economia de um país que servem de base para o desenvolvimento de outras atividades. Para que as empresas de um país possam exportar seus produtos, por exemplo, são necessários portos e aeroportos.

Além destes, também fazem parte de elementos de infraestrutura de um país, rodovias, usinas hidrelétricas, rodoviárias, sistemas de telecomunicação, ferrovias, rede de distribuição de água e tratamento de esgoto, sistema de transmissão de energia, entre outros. Vasconcellos (2012) aponta para o fato de que a estrutura logística é uma das principais contribuições para o custo de exportação pois a distância ao ponto de embarque para o exterior bem como as condições das vias (ferrovias, hidrovias e ferrovias) e veículos podem impactar significativamente no preço final do produto. 
Ainda segundo Gouvêa (2005), a infraestrutura é fundamental para o desenvolvimento econômico de um país. Sem ela, as empresas não conseguem desenvolver adequadamente seus negócios. Quando um país apresenta uma infraestrutura pouco desenvolvida, os produtos podem encarecer no mercado interno prejudicando os consumidores - e também no mercado externo - dificultando as exportações em função da concorrência mundial.

Dentro de muitas medidas, a qualificação da mão de obra e o crescimento da produtividade dentro do setor da construção civil encabeçam uma lista, das quais dizem, as prioridades para que o Brasil tenha um alto crescimento econômico e um controle no seu sistema inflacionário.

Como já dito anteriormente referente à importância da construção civil para a economia brasileira, nesta etapa, o texto tem o intuído de evidenciar tal importância olhando mais especifica para mão de obra. Tal etapa do texto tem o intuído de evidenciar de como uma baixa capacitação da mão de obra pode influenciar a saúde econômica de um país em desenvolvimento como o Brasil.

Segundo Monteiro (2013), o prolongado período de inflação elevada que afligiu os brasileiros por duas décadas despertou 0 interesse permanente pelo acompanhamento e análise dos diferentes índices de inflação divulgados mensalmente no país, mesmo já tendo decorrido 18 anos da adoção do plano real no governo de Itamar Franco (1992-1994), que obteve êxito no objetivo de reduzir a inflação e mantê-la em níveis aceitáveis. A fim de conter esse medo da volta do fantasma da inflação, o ministério da fazendo colocou uma tarefa ao Banco central para controla-la. Uma das obrigações do Banco para cumprir essa missão, o mesmo, adota desde 1999, uma modelo de politica monetária conhecido por Regime de Metas de Inflação. 


\section{Gráfico 03: Custo Total do Metro Quadrado, Materiais e Mão de Obra para Empreendimentos em 2012 (por Mil Reais)}

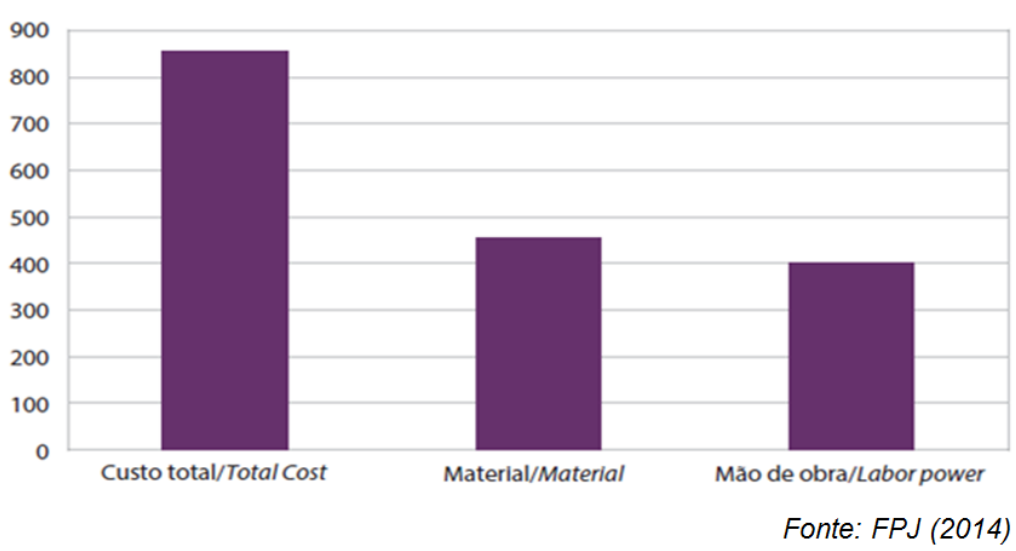

Dentro de diversos mecanismos que o Banco Central utiliza para acompanhamento do andamento da inflação, a qualificação da mão de obra tem sido apontada pela instituição como um dos acontecimentos que mais elevam a taxa inflacionária. O Gráfico 03 - Custo Total do Metro Quadrado, Materiais e Mão de Obra para Empreendimentos em 2012 (por Mil Reais) apresenta o custo por metro quadrado de uma obra naquele ano, destacando os componentes de materiais e mão de obra.

\section{2- QUALIFICAÇÃO E PRODUTIVIDADE DA MÃO DE OBRA}

Muitas empresas tem como norma para contratação de mão de obra direta em seus canteiros, um nível mínimo de experiência no cargo, como a Petrobras, por exemplo. Esta empresa tem se preocupado muito com a falta de mão de obra qualificado no setor de petróleo e gás, para isto, ela tem desenvolvido programas de formação de recursos humanos para o setor, em parceria com a ANP (Agencia Nacional de Petróleo, Gás Natura e Bicombustíveis). Entre eles estão o programa Ciência Sem Fronteiras e o PFRH (Programa Petrobras de Formação de Recursos Humanos).

O Programa Ciência Sem Fronteiras oferece recursos para a participação de alunos de graduação e doutorado com interesse em estudar no exterior temáticas relacionadas à tecnologia e à inovação. Estão inseridos nele, algumas linhas específicas para investir: entre elas estão energias renováveis e ciências do mar. Já o 
PFRH investe em bolsas de estudo no Brasil para estudantes de níveis técnico e superior (graduação, mestrado e doutorado), coordenadores e pesquisadores visitantes do setor de petróleo, gás e biocombustíveis, assim como melhorias nas condições de ensino e infraestrutura nas instituições parceiras.

Existem também investimentos em iniciativas como Programa de Mobilização da Indústria de Petróleo e Gás Natural (Prominp), criado pelo Governo Federal em 2003 em articulação com empresas da área. Sendo que a Petrobras é a principal financiadora dos cursos de qualificação gratuita do programa. Dentro do Prominp, há diversas iniciativas de qualificação de pessoal técnico para trabalhar na indústria do petróleo. Para o biênio 2014-2015 estão previstos mais de 17.000 qualificações nos cursos. (informações retiradas no site da Petrobras).

Restringindo para Construção Civil, a estatal tem diversas medidas que fazem, de acordo com estudiosos da área, a destacam perante outras empresas graças a sua evolução, com procedimentos e diretrizes em seus métodos construtivos exigidos no ato da construção de suas obras, a exemplo:

* Para contratação de quais quer funcionário, são exigidos níveis mínimos de experiência e atestados de capacitação do funcionário;

* Independente do numero de funcionários, cada frente de serviço da obra é exigido um técnico de segurança do trabalho, um inspetor de qualidade e um encarregado;

* Comunicadores sociais e técnicos de meio ambiente, com intuído de diminuir os impactos sociais e ambientais da região da obra;

* Fiscalização continua, nos meios de transportes dos trabalhadores casaobra e obra-casa;

* Fiscalização nas instalações e alojamentos dos trabalhadores, para verificar suas condições de habitabilidade;

* Incentivo em programas de qualificação da mão de obra dos trabalhadores, como a instalação do projeto escola dentro de seus canteiros;

* Sistema de informatização alertando as frentes de serviço a respeito de incidências de raios próximo ao local de trabalho, reduzindo acidentes provenientes aos fatores climáticos, não só humano como material; 
- Fiscais, de segurança do trabalho, qualidade dos serviços, produção da obra, comunicação social da vizinhança a obra e técnicos ambientais.

- Pisos salariais exclusivos para seus empreendimentos, geralmente acima dos pisos salariais dos sindicados da construção civil;

- Cobrança de participação dos lucros para todos os funcionários.

Mesmo que o motivo possa ser muito mais uma necessidade emergencial de mão de obra com uma qualificação mínima para a construção da Usina Hidrelétrica, do que um projeto social (duração média de dois anos), sendo o importante analisar que o problema da falta de qualificação já esta atingindo esferas econômicas, sociais e ambientais.

O programa Acreditar, promovida pelo consórcio CSAC/Odebrecht, contou com o apoio do Governo Federal, Governo Estadual, Prefeitura Municipal, SENAI (Serviço Nacional de Aprendizagem Industrial) e URINON (Faculdade Interamericana de Rondônia), pois tinha propósito de contratar $70 \%$ da mão de obra local, e estudos apontavam anteriormente, que a região não conseguiria atender nem a metade do previsto.

Sem entrar no mérito de evolução da obra, o qual não cabe aqui este estudo, vale a pena ressaltar alguns acontecimentos interessantes, que no ponto de vista de especialistas da área, apontam como, certa evolução da construção civil pesada.

Antes de começar a obra física, isto é, ainda na fase de projeto, os responsáveis do empreendimento, tiveram a preocupação de primeiramente conhecer o local, para ver se a região seria capaz de atender as demandas de mão de obra necessária, não só para reduzir suas despesas, mais sim, para profissionalizar e qualificar a população, trazendo não só uma benfeitoria física, mais sim uma benfeitoria social. Cabendo apenas uma maior fiscalização e exigências dos governos ferais e estaduais, pois devido suas parcerias e consequentemente a injeção de dinheiro, tinha por dever em tornar o programa não só para atender a hidrelétrica e sim todas as obras de infraestrutura da região. Todo material didático desenvolvido para o programa foi de responsabilidade do consócio com incentivos do governo federal e estadual, estimou-se um gasto de mais de $R \$ 12$ milhões de reais no 
projeto, com meta de capacitar mais de 11 mil pessoas para as funções mais utilizadas na construção da hidrelétrica e consequentemente, para construção da infraestrutura pesada brasileira, de acordo com informações das empresas.

Santos (2010) menciona que a qualificação de um trabalhador vai além, de uma operação braçal e sequencial, como aconteceu nos períodos fordista e taylorista de produção, caracterizado como acumulação flexível. Em um processo de qualificação, o qual vai além do simples domínio da habilidade motora e disposição para cumprir ordens deve contemplar, acima de tudo, ampla formação geral e sólida base de conhecimentos tecnológicos. Não basta ao trabalhador saber realizar determinadas atividades: é preciso também que possua características tais como as capacidades de participação, iniciativa, raciocínio lógico e discernimento.

Conforme Melhado (2013), a indústria da construção civil possui características próprias que as diferenciam das demais, tais como:

* Participação de diversos setores com diferentes funções;

* Heterogeneidade dos bens e serviços que produz;

* Tradicionalismo;

* Significando que o processo de produção e ocupação não sofreu mudanças tecnológicas significativas;

* A inércia às alterações, por utilizar mão de obra intensiva e pouco qualificada com pouco acesso a um plano de carreira;

* Singularidade das obras;

* Ambiente de trabalho exposto às intempéries;

* Baixa qualificação e alta rotatividade da mão de obra.

Segundo Monteiro (2013), os trabalhadores da indústria da construção civil compõem a base da pirâmide social urbana, e, dentro os diversos ramos da atividade econômica, o setor aloca um grande contingente de trabalhadores. Sendo a qualificação destes um meio, para que estes trabalhadores sobrevivam no mundo de trabalho com dignidade, mas, para isso, precisam de formação básica escolar, para que possam acompanhar o conteúdo de qualquer programa de qualificação, dando efetividade em tais programas. 
O operário braçal não pode ser visto apenas como mão de obra mas sim como um cidadão comprometido, com responsabilidade e deveres. Sendo de extrema importância investir nas pessoas, aproveitando o potencial singular de cada individuo. Ao apresentar as oportunidades advindas da qualificação profissional perante a demanda de mão de obra para a construção civil, a Tabela 01 - Obras Previstas para o Programa de Aceleração do Crescimento 02 entre 2010 e 2014 apresenta alguns dos novos empreendimentos planejados e os valores investidos em cada um destes.

\section{Tabela 01: Obras Previstas para o Programa de Aceleração do Crescimento 02 entre 2010 e 2014}

\begin{tabular}{|c|c|c|c|}
\hline Nome & Abrangência & Investimento & Meta \\
\hline $\begin{array}{l}\text { CIDADE } \\
\text { MELHOR }\end{array}$ & $\begin{array}{l}\text { Saneamento, Prevenção em } \\
\text { Áreas de Risco, Mobilidade } \\
\text { Urbana e Pavimentação. }\end{array}$ & $\begin{array}{l}\text { RS } 57,1 \\
\text { bilhões }\end{array}$ & $\begin{array}{l}\text { enfrentar os principais } \\
\text { desafios das grandes } \\
\text { aglomerações urbanas, } \\
\text { propiciando melhor } \\
\text { qualidade de vida. }\end{array}$ \\
\hline $\begin{array}{l}\text { COMUNIDADE } \\
\text { CIDADÁ }\end{array}$ & $\begin{array}{l}\text { Unidades de Pronto-Atendimento } \\
\text { (UPA) e Unidades Básicas de } \\
\text { Saúde, Creches e Pré-escolas, } \\
\text { Quadras esportivas nas escolas, } \\
\text { Praças do PAC e Postos de } \\
\text { Polícia Comunitária. }\end{array}$ & $\begin{array}{l}\text { RS } 23 \\
\text { bilhões }\end{array}$ & $\begin{array}{l}\text { Presença do Estado nos } \\
\text { bairros populares, } \\
\text { aumentando a cobertura de } \\
\text { serviços. }\end{array}$ \\
\hline $\begin{array}{l}\text { MINHA CASA, } \\
\text { MINHA VIDA }\end{array}$ & $\begin{array}{l}\text { Minha Casa, Minha Vida, } \\
\text { Financiamento SBPE, } \\
\text { Urbanização de Assentamentos } \\
\text { Precários }\end{array}$ & $\begin{array}{l}\text { RS } 278,2 \\
\text { bilhões }\end{array}$ & $\begin{array}{l}\text { Redução do déficit } \\
\text { habitacional, dinamizando o } \\
\text { setor de construção civile } \\
\text { gerando trabalho e renda. }\end{array}$ \\
\hline $\begin{array}{l}\text { ÁGUAE LUZ } \\
\text { PARA TODOS }\end{array}$ & $\begin{array}{l}\text { Luz Para Todos, Água em Áreas } \\
\text { Urbanas e Recursos Hídricos }\end{array}$ & $\begin{array}{l}\text { RS } 30,6 \\
\text { bilhões }\end{array}$ & $\begin{array}{l}\text { Universalização do acesso à } \\
\text { água e à energia elétrica }\end{array}$ \\
\hline TRANSPORTES & $\begin{array}{l}\text { Rodovias, Ferrovias, Portos, } \\
\text { Hidrovias, Aeroportos, } \\
\text { Equipamentos para estradas } \\
\text { vicinais }\end{array}$ & $\begin{array}{l}\text { RS } 104,5 \\
\text { bilhões } \\
\text { (2011-2014) } \\
\text { e RS 4,5 } \\
\text { bilhões } \\
\text { (pós-2014) }\end{array}$ & $\begin{array}{l}\text { Consolidar e ampliar a rede } \\
\text { logistica, interligando os } \\
\text { diversos modais, garantindo } \\
\text { qualidade e segurança. }\end{array}$ \\
\hline ENERGIA & $\begin{array}{l}\text { Geração e Transmissão de } \\
\text { Energia Elétrica, Petróleo e Gás } \\
\text { Natural, Indústria Naval, } \\
\text { Combustiveis Renováveis, } \\
\text { Eficiência Energética, Pesquisa } \\
\text { Mineral. }\end{array}$ & $\begin{array}{l}\text { RS 465,5 } \\
\text { bilhões } \\
\text { (2011-2014) } \\
\text { e RS 627,1 } \\
\text { bilhões } \\
\text { (pós-2014). }\end{array}$ & $\begin{array}{l}\text { a segurança do suprimento a } \\
\text { partir de uma matriz } \\
\text { energética baseada em } \\
\text { fontes renováveis e limpas: } \\
\text { desenvolver as descobertas } \\
\text { no pré-sal, ampliando a } \\
\text { produção. }\end{array}$ \\
\hline
\end{tabular}

Fonte: Biancarelli (2009)

\section{3- CONCLUSÕES INICIAIS}

A situação brasileira é delicada, por se tratar de um setor com altos e baixos, a rotatividade do setor é muito alta e muito dependente a incentivos governamentais, nos quais são totalmente imprevisíveis. A volta da prosperidade no setor da construção civil depois de décadas de estagnação é fruto da emergência da nova 
classe média brasileira na presença se um alto déficit habitacional, bem como eventos internacionais como a Copa do Mundo e a Olimpíadas, programas como Minha casa e Minha Vida e as obras de infraestrutura do PAC têm aumentado a demanda no setor que enfrenta restrições do lado da oferta. Em particular, os diversos atores que atuam na construção civil têm apontado como grande obstáculo para sua expansão à disponibilidade da oferta de mão de obra na quantidade e na qualidade desejada (Neri 2011).

A oscilação entre a demanda por mão de obra na construção civil, devido, aos aquecimentos e desaquecimentos econômicos no setor, não justifica a falta de qualidade da mão de obra, onde políticas sérias, eficientes e eficazes, utilizando os efeitos do aquecimento frente ao futuro desaquecimento do setor, funcionando como possível reservatório de qualificação desta mão de obra que em um próximo ciclo econômico próspero, tal problema esteja em vias de resolução.

Estudiosos do assunto apontam que os jovens atualmente tendem a escolher ocupações menos braçais e quanto maior sua qualificação, menor será sua procura pela Construção Civil. O aumento vegetativo de escolaridade da nova juventude vai implicar em um menor numero de oferta de pessoas para a construção e não uma mão de obra melhor qualificada.

A discussão sobre a falta de mão de obra no Brasil, não é tão simples como parece. Tratar deste assunto parece não estar em acordo com o desemprego no Brasil. Segundo o Ojima (2013), o Brasil mostrou uma taxa de desocupação da economia brasileira no segundo trimestre de 2013 em 7,4\% de desemprego no país, isto é, milhares de habitantes sem trabalho. Porém o apagão da mão de obra, não trata da falta de trabalhadores disponíveis no mercado de trabalho, mas a falta de empregabilidade de sua grande maioria, e investimentos em pessoas. A definição do conceito de empregabilidade como capacidade profissional para candidatar-se a um emprego ou para manter-se no emprego frente a falta de capacidade profissional para se candidatar a um emprego ou para manter no emprego não se deve apenas à reestruturação do processo de trabalho com suas exigências de aquisição de novas e complexas competências profissionais no Brasil de hoje. 


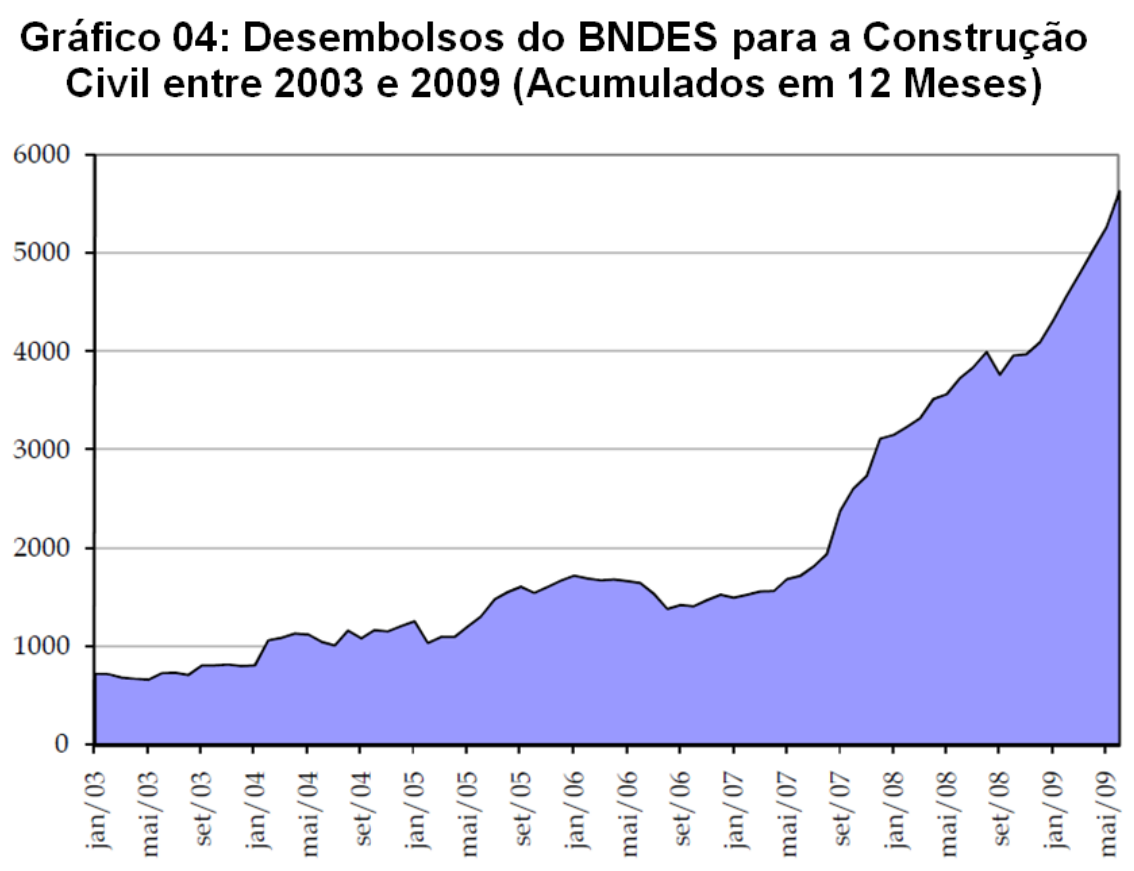

Fonte: Biancarelli (2009)

Finalmente, o Gráfico 04 - Desembolsos do BNDES para a Construção Civil entre 2003 e 2009 (Acumulados em 12 Meses) apresenta o potencial ganho advindo do crescimento econômico como uma oportunidade de qualificação da mão de obra e a potencialidade de melhor desempenho no ritmo de construção dos novos e futuros empreendimentos.

\section{REFERÊNCIAS}

BIANCARELLI, André. Panorama do Ciclo de Crédito Recente: Condicionantes e Características Gerais. Campinas: Editora UNICAMP, 2009.

CIDADES (Ministério das Cidades). Ações Integradas de Urbanização de Assentamentos Precários. Brasília: Imprensa Nacional, 2010.

FPJ (FUNDAÇÃO JOÃO PINHEIRO). Déficit Habitacional no Brasil: Resultados Preliminares 20112012. Belo Horizonte: Editora CEl/FPJ, 2014.

GOUVÊA, Ronaldo. A Questão Metropolitana no Brasil. Rio de Janeiro: Editora FGV, 2005.

IBGE (Instituto Brasileiro de Geografia e Estatística). Censo Demográfico 2010. Brasília: Editora IBGE, 2010.

MELHADO, Ana (Org). Projetar e Construir Bairros Sustentáveis. São Paulo: Editora Pini, 2013. 
MONTEIRO Filha, Dulce. Construção Civil no Brasil: Investimentos e Desafios. Rio de Janeiro: Editora BNDES, 2013.

MUNTEAL Filho, Oswaldo. Brasil em Números: Uma Breve História do Brasil. Rio de Janeiro: Editora IBGE, 2013.

OJIMA, Ricardo. Brasil em Números: População. Rio de Janeiro, Editora IBGE, 2013.

SANTOS, Milton. A Urbanização Desigual. São Paulo: EdUSP (3ª edição), 2010.

VASCONCELLOS, Eduardo. Mobilidade Urbana e Cidadania. Rio de Janeiro: Editora SENAC Nacional, 2012. 